\title{
WILEY
}

\section{Sources and uses of knowledge in a dynamic network technology}

\author{
Moriah Bostian $^{\mathrm{a}}$, Cinzia Daraio ${ }^{\mathrm{b}}$, Shawna Grosskopf ${ }^{\mathrm{c}}$, Giancarlo Ruocco ${ }^{\mathrm{d}, \mathrm{e}}$ and \\ William L. Weber ${ }^{\mathrm{f}, *}$ \\ a Department of Economics, Lewis and Clark College, Portland, OR 97219, USA \\ ${ }^{\mathrm{b}}$ Department of Computer, Control and Management Engineering A. Ruberti (DIAG), Sapienza University of Rome, \\ 00185 Rome, Italy \\ ${ }^{\mathrm{c}}$ Department of Economics, Oregon State University, Corvallis, OR 97331, USA \\ ${ }^{\mathrm{d}}$ Department of Physics, Sapienza University of Rome, 00185 Rome, Italy \\ ${ }^{\mathrm{e}}$ Center for Life Nano Science, Fondazione Istituto Italiano di Tecnologia (IIT), 00161 Rome, Italy \\ ${ }_{\mathrm{f}}^{\mathrm{f}}$ Department of Accounting, Economics and Finance, Southeast Missouri State University, Cape Girardeau, \\ MO 63701, USA \\ E-mail:mbbostian@lclark.edu [Bostian]; daraio@dis.uniromal.it [Daraio]; shawna.grosskopf@orst.edu [Grosskopf]; \\ giancarlo@orst.edu [Ruocco]; wlweber@semo.edu [Weber]
}

Received 6 January 2019; received in revised form 13 September 2019; accepted 8 October 2019

\begin{abstract}
We estimate a dynamic network technology where new knowledge in the form of publications in STEM (science, technology, engineering, and mathematics) is an intermediate product. Knowledge is produced in the first stage of production and is used in the second stage of production to produce a final output of real consumption, which equals gross domestic product minus investment spending on physical capital minus research and development expenditures. Knowledge also spills over between producers as it becomes disseminated. The two stages of production are linked between periods as investments in research capital and physical capital enhance future production possibilities. Our model combines several theories of production: dynamic data envelopment analysis (DEA) and two-stage network DEA. Using pooled data on 53 countries during 1999-2012, the model estimates indicate that dynamic efficiency averages about $70 \%$. Countries could increase final consumption by about $25 \%$ via greater technical efficiency in production and by another $5 \%$ via an optimal intertemporal reallocation of investment spending.
\end{abstract}

Keywords: dynamic network; intermediate products; knowledge

\section{Introduction}

Since the work of Solow (1956), there has been much research on the optimal path of investment spending and its relation to productivity growth. Productivity growth contributes to economic

${ }^{*}$ Corresponding author. 
well-being as more outputs are produced using fewer inputs. Such growth occurs when producers become more efficient at using a known technology or when technical change occurs. Here we model the sources and role of knowledge in productivity growth, focusing specifically on knowledge production by researchers in STEM (science, technology, engineering, and math). The National Science Foundation (NSF) was started in 1945 by President Roosevelt to promote research and education in STEM fields (Rothwell, 2013). Research and development (R\&D) in STEM fields has been shown to be an important driver of productivity growth, with estimates that R\&D growth contributes between $30 \%$ and $70 \%$ of productivity growth (Adams, 1990; Jones, 2002; Peri et al., 2015).

Research is undertaken by public sector organizations such as public universities and various government agencies and in the private sector by private universities, nonprofit organizations, and for-profit firms. When published, this new knowledge takes on characteristics of a public good, being both nonrival and nonexcludable. Adams (1990) found knowledge in science, engineering, and mathematics, and knowledge spillovers contributed over half the productivity growth in U.S. manufacturing industries from 1953 to 1980. Jones (2002) attributed 50-70\% of labor productivity growth during 1950-1993 to greater research intensity as measured by the number of scientists and engineers engaged in R\&D in G-5 countries. Peri et al. (2015) found that employment growth among foreign STEM researchers residing in the United States explained between $30 \%$ and $50 \%$ of productivity growth in the 100 largest U.S. cities.

In this paper, we seek to better understand how advances in the STEM disciplines contribute to economic growth and determine the optimal allocation of resources devoted to these areas. To do this, we develop a dynamic network model that incorporates STEM knowledge production as an intermediate product in the macroeconomy, allowing for knowledge spillovers across disciplines. New knowledge is used to produce final output, and this knowledge spills over and can be used by other producers. The optimization problem we develop and estimate seeks the maximum expansion in final outputs that can be achieved via greater production efficiency due to an optimal intertemporal reallocation of resources. Our model is related to the work of Romer (1990) who assumed that technological change occurs because of "intentional actions taken by people who respond to market incentives" (Romer, 1990, p. S72). Furthermore, we assume that the publications that are produced at a given point in time are initially excludable, but then become nonrival and nonexcludable in later periods. An important result of Romer (1990) is that capital will be underallocated to a research sector for two reasons: first, because private producers are unable to capture all of the benefits of research, and second, because of monopoly pricing of the private good. In addition to determining the degree to which an intertemporal reallocation of resources can expand final output, we also empirically investigate Romer's theory that resources are underallocated to $\mathrm{R} \& \mathrm{D}$.

As researchers produce knowledge, not only does their own ability to produce knowledge expand, that knowledge also spills over to researchers at other universities and private organizations as it becomes more widely known. These knowledge spillovers, across disciplines (see Daraio et al., 2018), countries, and time increase the knowledge base and link research to private sector productivity. We consider these linkages as a form of network technology where knowledge is an intermediate product used to produce other goods and services. This dynamic network framework allows us to consider reallocations of knowledge resources through time in order to better capitalize on knowledge spillovers and enhance economic growth. 
From a methodological point of view, we develop an efficiency analysis approach based on the estimation of efficient frontiers. This literature is constantly growing as it is witnessed by the increasing number of reviews published in the literature (for recent surveys, see, e.g., Narbón-Perpiñá and De Witte, 2018; Catalano et al., 2019; Daraio et al., 2020). Our model combines several theories of production: dynamic data envelopment analysis (DEA) and two-stage network DEA. Dynamic network analyses based on DEA can be found in Tran and Villano (2018), Moreno and Lozano (2018), Hsiao et al. (2019), and Chen et al. (2020).

We combine bibliometric data (e.g., publications, citations, authors) with aggregate data on public and private research investment, as well as other macroeconomic variables (e.g., real gross domestic product [GDP], employment), to construct an international panel for 53 countries and 18 STEM disciplines for the years 1996-2012. We use this panel to consider the potential reallocation of investment between research and industry, through the lens of our dynamic network model of linked research and industry production technologies. Consistent with the theoretical result of Romer (1990), we find that the optimal ratio of research investment to industrial investment generally exceeds that ratio in practice. Reallocations of investment spending across periods along with changes in the mix of investments in physical capital versus research capital offer the potential to expand GDP by an average of $5 \%$.

We provide several contributions to the literature by building a two-stage network model with knowledge as an intermediate product; by accounting for knowledge spillovers between countries; by extending the network model to a dynamic model that allows two types of trade-offs between final consumption and investment spending, and between investment spending on physical capital and investment spending on research capital where the objective is to maximize the sum of final consumption across all periods; and finally, by offering some empirical evidence of Romer's theory that resources are underallocated to $\mathrm{R} \& \mathrm{D}$.

In the next section, we overview the related literature on knowledge spillovers in more detail. We then provide some background on network production models in this context, before introducing our own dynamic network model of knowledge production in Section 3. We detail the application and results in Section 4 and conclude with a final discussion in Section 5.

\section{Related literature}

We develop a dynamic network model of production that accounts for international spillovers of knowledge. Knowledge transfers from the R\&D sector to the industrial sector and back again are captured within our model. Even as knowledge is incorporated into new techniques by its user, that knowledge also spills over and affects other producers. Measuring knowledge is fraught with difficulties and this section also reviews research on the difficulties and limitations of designing meaningful knowledge indicators.

To measure knowledge spillovers requires consistent and widely available indicators of knowledge produced. One point to emerge from the literature concerns the measurement and quantification of knowledge itself. Bibliometric data on publications and citations have been recognized as knowledge outputs, but international comparisons of productivity in R\&D are limited by a paucity of comparable data (Aksnes et al., 2017). This presents several challenges for cross-country analysis. First, one must correctly count publications/citations when co-authors reside in more than one 
country. Second, although citation indexes such as the Web of Science and Scopus provide fairly wide coverage of some fields such as the natural sciences, these indexes are more limited in their coverage of papers in the humanities, social sciences, and engineering. To the extent that countries realize a comparative advantage in these thinly covered fields, their performance estimates will be biased downward. Third, inquiries into the presence or absence of statistical power and bias in economics (Ioannidis et al., 2017) and other scientific research (Ioannidis, 2005) has found that many published results are a reflection of the prevailing bias and are likely false. Fourth, even if the above challenges are met, new research findings are necessarily heterogeneous, so that publication counts might not be an accurate measure of knowledge production (Foray, 2004). Finally, research grants received might be a more accurate measure of research quantity and quality since grants imply a willingness to pay for the research conducted (Johnes and Johnes, 1993; Agasisti and Haelermans, 2016).

Recent research on the scientific impact of nations identified the United States and United Kingdom as the top two leaders in highly cited publications from 1997 to 2001 (King, 2004), Iran and Saudi Arabia as scientific leaders in the Gulf states (Moed, 2016), and China as the fifth leading country in scientific publications with $6.5 \%$ of the world's total publications in 2004 compared to the $8.3 \%$ publications in the United Kingdom and $30.5 \%$ publications in the United States (Zhou and Leydesdorff, 2006). Moed and Galevi (2014) found that Iran and China had high growth rates in publications relative to other countries with similar levels of publications and that regional collaboration between countries in Asia acts as a stepping stone to greater international scientific collaborations.

Gralka et al. (2018) control for teaching and estimate the research efficiency of 72 German public universities using grants, publications, and highly cited publications as alternative measures of research output. They find a high positive correlation between the measures of efficiency, which they take "as a sign that universities which are good in acquiring third party funds are the ones which are equally good in publishing high-quality research" (Gralka et al., 2018, p. 6).

Another important point to emerge concerns the flow of knowledge between academic research and the private sector, commonly termed as "university-industry knowledge transfer." Our dynamic network model described in the next section can be specified to capture these linkages. One form of knowledge transfer occurs when university researchers collaborate with industry researchers. Tartari et al. (2014) find evidence that this collaboration is more likely when the departmental peers of a researcher also collaborate with industry and support this finding by arguing that researchers compare themselves and compete with their fellow departmental researchers. Perkmann et al. (2013) examine various aspects of academic engagement between universities and industry including collaborative research, contract research, consulting, and informal engagement and write that "academic engagement often precedes commercialization in time and can hence be regarded as an input factor to the latter. Academic engagement may also accompany commercialization, for instance when spin-off companies work collaboratively with the university labs they originated from" (Perkmann et al., 2013, p. 424). In a network model, such engagement would typically comprise a two-way flow where universities produce and receive intermediate products from industry. Jaffe (1989) provides evidence that university research causes industrial R\&D, but not vice versa. Our aggregated country data do not allow us to distinguish between university publications and industry publications. However, if such data were available our network model 
can be easily adapted to represent the two-way flow between academic research and industry production.

In 1980, university-industry transfers in the United States received a boost from passage of the Bayh-Dole Act, which allowed universities to patent and license inventions from research that had received Federal funding. One purpose of the Act was to provide incentives for universities to engage in more research, with an intended outcome of increased patenting. However, Mowery and Sampat (2005) report that university-industry transfers had already increased in the pre-BayhDole period and that lobbying by U.S. research universities contributed to passage of the Act. Thus, passage of Bayh-Dole might have been "as much an effect as a cause of expanded patenting and licensing by US universities" (Mowery and Sampat, 2005, p. 237). In the early 2000s, Germany, Austria, Denmark, Finland, and Norway ended the "professor's privilege" where university researchers enjoyed full rights to their inventions and intellectual property and moved toward patenting and licensing policies similar to Bayh-Dole. Hvide and Jones (2018) find a 50\% decline in entrepreneurship and patenting among professors in Norway after the end of the "professor's privilege."

Since research dollars and time can be used to produce a mix of basic research and applied research, there was some concern that Bayh-Dole would tip the scale too far away from nonexcludable basic research toward applied research, which is more easily excludable. Weber and Xia (2011) and Fukuyama et al. (2016) review research on the applied/basic research trade-off. Some research supports the idea that universities gain monopoly power from licensing inventions and that monopoly power favors resources going into industrial applications (Boldrin and Levin, 2009; Just and Huffman, 2009; Weber and Xia, 2011). Other research finds that applied research and basic research are complements rather than substitutes (Thursby and Thursby, 2002; Fabrizio and DeMinin, 2008; Azoulay et al., 2009).

In a broader context than Bayh-Dole, Kealey (1996) even argues that many inventors experienced applied and economic success before scientists knew why their invention worked. Although our model incorporates only a money flow as the intermediate product, our dynamic model can also incorporate nonmonetary flows. For instance, even though patent holders get exclusive use of various types of applied research, scientists who cooperate with industry can learn more about whether their theories are validated (Perkmann et al., 2013). See also the classic paper by Comanor and Scherer (1969, p. 398) and their conclusion that "patent statistics may be a better index of research input than output." This further highlights the connections between academic and industry research. The next section outlines our use of network production theory to model these connections.

\section{Network models}

In practice, the production of final goods and services often occurs in stages, where output from one stage becomes an input in subsequent stages. As a simple example, the stages of production for a wooden chair might include harvesting the timber, milling the lumber, and then crafting the furniture. This linkage of production, via intermediate products (i.e., the timber and milled wood), constitutes a network production technology. Here, we draw on network production methods to 
model the formation of new knowledge, and in turn, its contribution to the production of other goods and services in the economy.

Before turning to our dynamic network model, we first introduce a static network model where knowledge is produced in the first stage of production and then subsequently used as an input in the second goods' producing stage using what are called distance functions to represent technology and assess performance. Distance functions are a generalization of production functions and have been used to represent multiproduct knowledge technologies, accommodating specification of many outputs and inputs.

These functions, along with duality theory, have been used to estimate shadow prices for knowledge spillovers between universities (Weber, 2019), to estimate elasticities of transformation between knowledge outputs of patents, Ph.D. students, and publications (Weber and Yin, 2011), and to simulate a reallocation of NSF funds given to enhance knowledge outputs at various U.S. institutions of higher education (Fukuyama et al., 2016). Distance functions can be estimated parametrically (Weber and Xia, 2011; Weber, 2019) or using nonparametric DEA (Fukuyama et al., 2016). We extend these models and use a dynamic network distance function to model the role that knowledge plays in a dynamic network technology.

\subsection{Overview of previous network production models}

Distance functions have been widely used to estimate producer performance. Early models were static black box representations of a production technology. More recent work has extended these models to account for network production where intermediate products are first produced and then used to produce final outputs. Intermediate products are a key feature of network models (Färe and Grosskopf, 1996a, 1996b, 2000; Prieto and Zofío, 2007; Bogetoft et al., 2009). Such products tend to be outputs of one division or production stage and inputs to another division or production stage. Kao $(2014,2017)$ lays out the theoretical foundation and reviews and extends the many forms that network models take. Bostian et al. (2018) examine interdisciplinary knowledge productivity spillovers among 16 STEM fields in a statistical network setting. They find higher interactions between some fields such as physics and materials science and between chemistry and chemical engineering, but low or zero interactions among other fields, such as biochemistry and computer science and between medicine and mathematics.

When the network technology extends over several periods, we call it a dynamic network technology. Färe et al. (2018) provide an overview of various types of dynamic network models. FallahFini et al. (2014) identify five factors that lead to an intertemporal dependence between inputs and outputs: production delays, inventories, quasi-fixed factors such as capital, adjustment costs, and learning models. A decision-making unit (DMU) exhibits dynamic efficiency when it "cannot shift production from one period to another and generate a larger present value of the firm's utility" (Fallah-Fini et al., 2014, p. 53). See also the review of dynamic models by Mariz et al. (2018).

In education, a network might consist of a school district with primary and secondary school types where administrators seek to allocate their budget across school types and between schools of the same type so as to maximize some preferred educational outcome. Grosskopf et al. (2017) use a static network DEA model to simulate the effects of weighted-student funding on primary 
and secondary Texas' school districts. Shen et al. (2016) use an input/output network model to prioritize and determine which subfields of physics act as support or are supported by a given field. Using citations as the intermediate product, they find that there can be strong links between subfields (such as quantum mechanics and mechanic control) even when there are few direct citations between them. They also find that statistical physics supports many other subfields, but relativity has a much weaker influence on other subfields.

Our interest lies in two linked processes: the formation of new knowledge from existing knowledge and the subsequent role that new knowledge plays in the production of final goods and services in the economy. This first process can be considered the research stage, where we measure knowledge in terms of research publications and citation counts. In the research process, knowledge builds on the work of others, so that existing publications lead to new publications, with the latter citing the former. The second process can be considered the product development stage, where producers harness new knowledge flowing from the initial research stage to produce final goods and services in the economy. We consider these linked processes in a dynamic sense, the key distinction being the potential to reallocate resources in the economy between the two stages of production. Important resources include capital, decomposed into knowledge capital (e.g., lab space and equipment) and physical production capital (e.g., factories and machinery), and labor employed at each stage (e.g., research authors, manufacturing workers).

The dynamic aspect of the model allows producers to choose intermediate production at different points in time in order to maximize the weighted sum of final outputs over time. Thus, when technical progress is expected, producers might find it optimal to forgo final consumption in $t$ and instead, produce the two intermediate products in order to expand future final consumption. Furthermore, standard microeconomic theory requires investments to be made to equalize the marginal products of physical capital and knowledge capital to future final output across time. Comparing the actual versus the optimal timing and quantities of the two intermediate products allows us to infer whether dynamic efficiency is increasing or decreasing. In addition, comparing the actual mix of the two intermediate products with the optimal mix can help inform policy makers about the relative marginal products of physical capital and knowledge capital.

Here we mention only a small subset of research that uses DEA in a dynamic framework. Building on the work of Ramsey (1928), Färe and Grosskopf (1996a, 1996b, 1998) and Sengupta (1996) develop dynamic models where current decisions on capital investment impact future production possibilities (see also Nemoto and Goto 2003; Silva and Stefanou, 2003; Ouellette and Yan, 2008; Serra et al., 2011; Sacoto et al., 2015). In an infinite horizon model, Lansink et al. (2015) and Silva et al. (2015) choose investment spending to minimize the present value of all future costs of production. Färe et al. (2012) and Fukuyama and Weber (2015) examine dynamic efficiency and productivity when undesirable outputs, such as pollution or nonperforming loans, are part of the technology. Fukuyama et al. (2016) use DEA to simulate the dynamic reallocation of NSF funds for nanobiotechnology across universities so as to maximize knowledge outputs of publications, patents, and Ph.D. students. In general, these studies found that efficiency gains could be realized by an intertemporal reallocation of resources. In the context of knowledge production, this intertemporal reallocation might be stymied by producers who are unable to capture all of the benefits of their own actions, such as occurs when knowledge is a public good or has positive spillover effects. 
Table 1

Model notation

\begin{tabular}{llll}
\hline Static & & Dynamic & \\
\hline$y$ & Real GDP & $f y$ & Final consumption \\
$L$ & Employment & $i y_{1}$ & Research investments \\
$A$ & Authors & $i y_{2}$ & Physical capital investments \\
$c 1$ & Knowledge capital & $\gamma$ & Depreciation of research capital \\
$c 2$ & Real physical capital & $\delta$ & Depreciation of physical capital \\
$z_{1}$ & Own publications & & \\
$z_{2}$ & Own publication quality & & \\
$\tilde{z}$ & Spillover publications of others & & \\
\hline
\end{tabular}

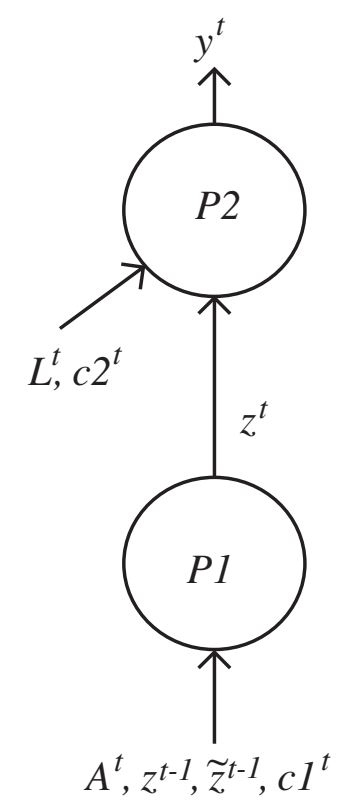

Fig. 1. Static technology.

\subsection{The static network model}

Before turning to the model, we introduce the associated notation (both static and dynamic) for reference in Table 1.

We begin with the static version of our aggregated network model before extending it to the dynamic case. Figure 1 illustrates a static network with two stages of production. In the first stage, country $k$ produces new research knowledge, $z_{k}^{t}$, using authors, $A_{k}^{t}$, research capital, $c 1_{k}^{t}$, and past research knowledge, where $t=1, \ldots, T$ represents the time period that we take to be one year. Past research knowledge enters stage 1 in two ways: first, $k$ draws on its own stock of knowledge from $t-1$ to produce new research in $t$. Second, the researchers in $k$ also gain access to the research produced by researchers in other countries. This spillover effect input is $\tilde{z}_{k}^{t-1}=\sum_{j \neq k}^{K} z_{j}^{t-1}$. We distinguish between own past publications $\left(z_{k}^{t-1}\right)$ and past external publications $\left(\tilde{z}_{k}^{t-1}\right)$ because 
there are various geographic constraints that differentially affect the transmission of knowledge. For instance, a common language within a country provides easier communication of ideas within that country. Researchers within a country might also have access to a library consortium that shares materials. Dropping the $k$ subscript, we write stage 1 production technology as

$$
P 1^{t}=\left\{z^{t}:\left(A^{t}, c 1^{t}, z^{t-1}, \tilde{z}^{t-1}\right) \text { can produce } z^{t}\right\} .
$$

In stage 2, real GDP, $y^{t}$, is produced using labor, $L^{t}$, real physical capital, $c 2^{t}$, and the research knowledge produced in $P 1$. Stage 2 output set is

$$
P 2^{t}=\left\{y^{t}:\left(z^{t}, L^{t}, c 2^{t}\right) \text { can produce } y^{t}\right\} .
$$

Combining (1) and (2) gives the network technology for $t$ :

$$
N^{t}=\left\{\left(A^{t}, c 1^{t}, z^{t-1}, \tilde{z}^{t-1}, z^{t}, L^{t}, c 2^{t}, y^{t}\right): z^{t} \in P 1^{t} \text { and } y^{t} \in P 2^{t}\right\} .
$$

The Shephard (1970) output distance function is used as a functional representation of the network technology set, $N^{t}$. The reciprocal of this function gives the maximum proportional expansion in outputs that would be feasible if the DMU were to become efficient and produce on the frontier of the network technology given by (3). This distance function is

$$
D_{o}^{t}\left(A^{t}, c 1^{t}, z^{t-1}, \tilde{z}^{t-1}, c 2^{t}, L^{t}, y^{t}\right)=\min \left\{\phi: \frac{y^{t}}{\phi} \in N^{t}\right\}
$$

and is bounded between 0 and 1. Efficient DMUs have $D_{o}^{t}(\cdot)=1$ and inefficient DMUs have $D_{o}^{t}(\cdot)<1$.

We use DEA to represent the network technology. DEA constructs a best-practice frontier from the observed inputs and outputs of the $k=1, \ldots, K$ DMUs. The DEA method chooses intensity variables for the two stages, $\lambda_{1 k}^{t}$ and $\lambda_{2 k}^{t}, k=1, \ldots, K$, to make the largest convex set of feasible outputs and inputs such that the feasible inputs are no less than a linear combination of observed inputs and the feasible outputs are no greater than a linear combination of observed outputs. The DEA network technology set is

$$
\begin{aligned}
N^{t} & =\left\{\left(A^{t}, c 1^{t}, z^{t-1}, \tilde{z}^{t-1}, z^{t}, L^{t}, c 2^{t}, y^{t}\right):\right. \\
A^{t} & \geq \sum_{k=1}^{K} \lambda_{1 k}^{t} A_{k}^{t}, \quad c 1^{t} \geq \sum_{k=1}^{K} \lambda_{1 k}^{t} c 1_{k}^{t}, \quad z^{t-1} \geq \sum_{k=1}^{K} \lambda_{1 k}^{t} z_{k}^{t-1}, \\
\tilde{z}^{t-1} & \geq \sum_{k=1}^{K} \lambda_{1 k}^{t} \tilde{z}_{k}^{t-1}, \quad z^{t} \leq \sum_{k=1}^{K} \lambda_{1 k}^{t} z_{k}^{t}, \quad \lambda_{1 k}^{t} \geq 0, k=1, \ldots, K, \quad t=1, \ldots, T, \\
z^{t} & \geq \sum_{k=1}^{K} \lambda_{2 k}^{t} z_{k}^{t}, L^{t} \geq \sum_{k=1}^{K} \lambda_{2 k}^{t} L_{k}^{t}, \quad c 2^{t} \geq \sum_{k=1}^{K} \lambda_{2 k}^{t} c 2_{k}^{t}, \\
y^{t} & \leq \sum_{k=1}^{K} \lambda_{2 k}^{t} y_{k}^{t}, \quad \lambda_{2 k}^{t} \geq 0, k=1, \ldots, K, \quad t=1, \ldots, T .
\end{aligned}
$$


The two stages of production are linked through the intermediate product of research knowledge. In stage 1 , the research output constraint is $z^{t} \leq \sum_{k=1}^{K} \lambda_{1 k}^{t} z_{k}^{t}$ and in stage 2 the research input constraint is $z^{t} \geq \sum_{k=1}^{K} \lambda_{2 k}^{t} z_{k}^{t}$. Together these two constraints imply that

$$
\sum_{k=1}^{K} \lambda_{1 k}^{t} z_{k}^{t} \geq z^{t} \geq \sum_{k=1}^{K} \lambda_{2 k}^{t} z_{k}^{t}, \quad t=1, \ldots, T,
$$

meaning that the intensity variables must be chosen so that stage 2 cannot use more of the input $z^{t}$ than was produced in stage 1.

Using (5), the reciprocal of the output distance function is estimated as

$$
D_{o}^{t}\left(A^{t}, c 1^{t}, z^{t-1}, \tilde{z}^{t-1}, z^{t}, L^{t}, c 2^{t}, y^{t}\right)^{-1}=\max _{\phi, \lambda_{1}, \lambda_{2}} \phi^{-1} \quad \text { subject to } y^{t} \phi^{-1} \in N^{t},
$$

where the choice variables in (7) are the expansion factor $\phi^{-1}$ and the intensity variables for the two stages of production, $\lambda_{1 k}^{t}$ and $\lambda_{2 k}^{t}, k=1, \ldots, K$.

\subsection{Dynamic network model}

We extend the static network model to a dynamic model by decomposing real GDP into final consumption and two types of investment spending. Real GDP equals the sum of final consumption, $f y^{t}$, and the two types of investment: $y^{t}=f y^{t}+i y 1^{t}+i y 2^{t}$, where $i y 1^{t}$ are research investments that flow to stage 1 in $t+1$ and $i y 2^{t}$ are physical capital investments that flow to stage 2 in $t+1 .^{1}$ Investments made in $t$ expand production possibilities in period $t+1$. Thus, the producer has several decisions to make. First, should resources be used to produce current final output or future outputs? Second, the two types of investment alter subsequent production in different ways. Research investments, $i y 1^{t}$, are an input to stage 1 in $t+1$ while physical capital investments, $i y 2^{t}$, are an input to stage 2 in $t+1$. Thus, what is the relative optimal mix of the two intermediate products?

We assume that research capital $(c 1)$ depreciates at rate $(1-\gamma)$. Therefore, the available research capital available in $t+1$ equals the depreciated value of research capital from $t$ plus $i y 1^{t}$ :

$$
c 1^{t+1}=\gamma c 1^{t}+i y 1^{t}
$$

Similarly, real physical capital $(c 2)$ depreciates at rate $(1-\delta)$ so that available real physical capital in $t+1$ equals the depreciated the amount of real physical from $t$ plus $i y 2^{t}$ :

$$
c 2^{t+1}=\delta c 2^{t}+i y 2^{t}
$$

The dynamic network technology is

$$
D N=\left\{\left(z^{t}, y^{t}\right):\left(z^{t}, y^{t}\right) \in N^{t}, t=1, \ldots, T\right\}
$$

and is illustrated in Fig. 2.

${ }^{1}$ Our method can be extended to cases in which there are multiple final outputs. 


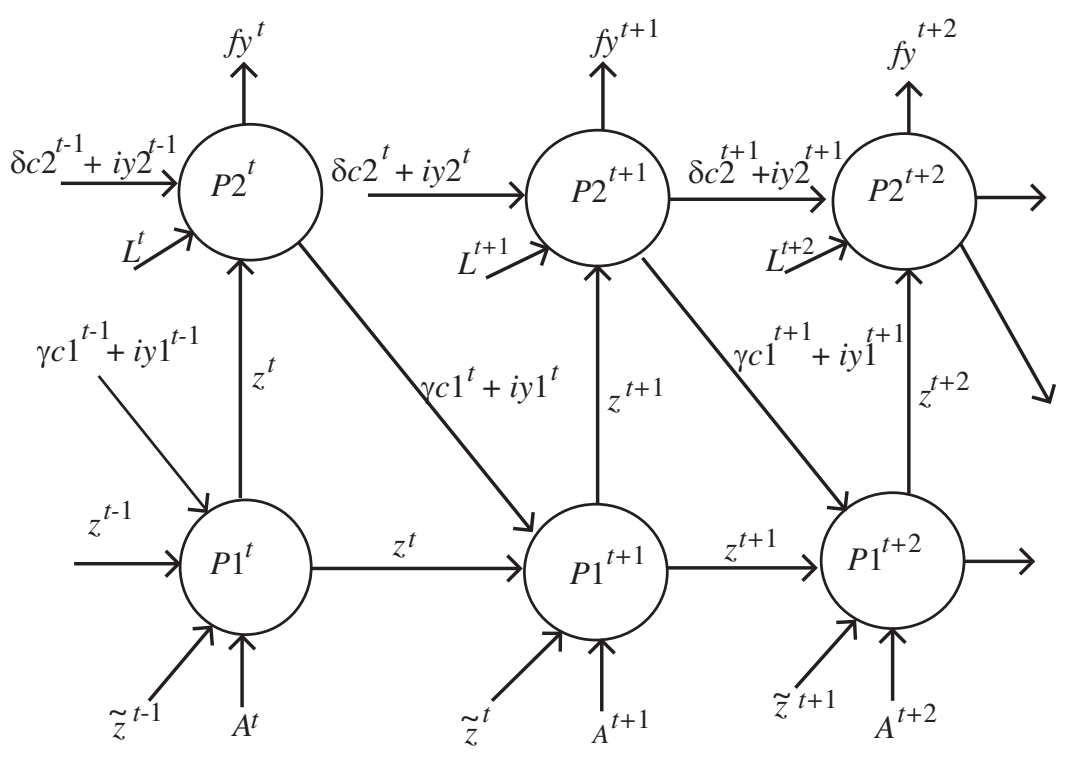

Fig. 2. Dynamic network technology.

Our dynamic optimization problem maximizes the sum of weighted final outputs across all periods by choosing the amounts of the two intermediate products:

$$
\begin{aligned}
\operatorname{maximize} & \sum_{t=1}^{T} \Psi^{t} \phi^{-1, t} \text { subject to } \\
& \left(z^{t}, \phi^{-1, t} y^{t}\right), t=1, \ldots, T \in D N,
\end{aligned}
$$

where $\Psi^{t}, t=1 \ldots, T$ are predetermined weights that account for the DMU's rate of time preference. For instance, if the opportunity cost of capital is $r$, the weights might be chosen as $\Psi^{t}=1 /(1+r)^{t-1}$.

We impose initial and terminal conditions for research capital and real physical capital. For DMU $o$ in $t=1$, we take research capital and physical capital as given by their observed values, $c 1_{o}^{1}$ and $c 2_{o}^{1}$. In the terminal period, $T$, we take the investments in research capital and physical capital for DMU $o$ as given by their observed values: $i y 1_{o}^{T}$ and $i y 2_{o}^{T}$. The optimization problem chooses two types of investment in $t=1, \ldots, T-1$. Let these optimal intermediate products be $i y 1^{t *}$ and $i y 2^{t *}$, $t=1, \ldots, T-1$. Thus, in $t=2, \ldots, T$, the amounts of research capital and physical capital equal the depreciated value of the capital stock from the previous period plus investment. For instance, in $t=2$ research capital equals $c 1_{o}^{2}=\gamma c 1_{o}^{1}+i y 1^{1 *}$ and physical capital equals $c 2_{o}^{2}=\delta c 2_{o}^{1}+i y 2^{1 *}$. In $t=3$, the two types of capital are $c 1_{o}^{3}=\gamma^{2} c 1_{o}^{1}+\gamma i y 1^{1 *}+i y 1^{2 *}$ and $c 2_{o}^{3}=\delta^{2} c 2_{o}^{1}+\delta i y 2^{1 *}+i y 2^{2 *}$. We write these two optimal capital stocks as

$$
\begin{aligned}
& c 1_{o}^{t *}=\gamma^{t-1} c 1_{o}^{1}+\sum_{\tau<t} \delta^{t-\tau-1} i y 1^{\tau *}, t=2, \ldots, T, \\
& c 2_{o}^{t *}=\delta^{t-1} c 2_{o}^{1}+\sum_{\tau<t} \gamma^{t-\tau-1} i y 2^{\tau *}, t=2, \ldots, T .
\end{aligned}
$$


Note that the superscripts on $\gamma$ and $\delta$ are raising those variables to a power to account for depreciation, whereas the $t$ superscripts on the other variables, $A^{t}, c 1^{t}, c 2^{t}, z^{t}, \tilde{z}^{t}, L^{t}, y^{t}$, and $f y^{t}$ represent the time period.

In the static model, the output constraint for stage 2 is $y^{t} \leq \sum_{k=1}^{K} \lambda_{2 k}^{t} y_{k}^{t}$. Our dynamic network program modifies stage 2 output constraint by decomposing total output, $y^{t}$, into its additive components of final consumption output and the two intermediate products. The dynamic stage 2 output constraint for $t$ is $f y^{t}+i y 1^{t}+i y 2^{t} \leq \sum_{k=1}^{K} \lambda_{2 k}^{t} y_{k}^{t}$.

The DEA optimization problem for DMU $o$ is

$$
\begin{aligned}
& \underset{\phi, \lambda_{1}, \lambda_{2}, i y 1, i y 2}{\operatorname{maximize}} \sum_{t=1}^{T} \Psi^{t} \phi^{-1, t} \text { subject to } \\
& \quad \operatorname{in} t=1 \\
& A_{o}^{1} \geq \sum_{k=1}^{K} \lambda_{1 k}^{1} A_{k}^{1}, \quad c 1_{o}^{1} \geq \sum_{k=1}^{K} \lambda_{1 k}^{1} c 1_{k}^{1}, \quad z_{o}^{0} \geq \sum_{k=1}^{K} \lambda_{1 k}^{1} z_{k}^{0}, \quad \tilde{z}_{o}^{0} \geq \sum_{k=1}^{K} \lambda_{1 k}^{1} \tilde{z}_{k}^{0}, \\
& z_{o}^{1} \leq \sum_{k=1}^{K} \lambda_{1 k}^{1} z_{k}^{1}, \quad z_{o}^{1} \geq \sum_{k=1}^{K} \lambda_{2 k}^{1} z_{k}^{1}, \quad L_{o}^{1} \geq \sum_{k=1}^{K} \lambda_{2 k}^{1} L_{k}^{1}, \quad c 2_{o}^{1} \geq \sum_{k=1}^{K} \lambda_{2 k}^{1} c 2_{k}^{1}, \\
& \phi^{-1,1} f y_{o}^{1}+i y 1^{1}+i y 2^{1} \leq \sum_{k=1}^{K} \lambda_{2 k}^{1} y_{k}^{1}, \quad \lambda_{1 k}^{1} \geq 0, \quad \lambda_{2 k} \geq 0, \quad k=1, \ldots, K
\end{aligned}
$$

in $t=2, \ldots, T-1$

$$
\begin{aligned}
& A_{o}^{t} \geq \sum_{k=1}^{K} \lambda_{1 k}^{t} A_{k}^{t}, \quad \gamma^{t-1} c 1_{o}^{1}+\sum_{\tau<t} \gamma^{t-\tau-1} i y 1^{\tau} \geq \sum_{k=1}^{K} \lambda_{1 k}^{t} c 1_{k}^{t}, \quad z_{o}^{t-1} \geq \sum_{k=1}^{K} \lambda_{1 k}^{t} z_{k}^{t-1}, \\
& \tilde{z}_{o}^{t-1} \geq \sum_{k=1}^{K} \lambda_{1 k}^{t} \tilde{z}_{k}^{t-1}, \quad z_{o}^{t} \leq \sum_{k=1}^{K} \lambda_{1 k}^{t} z_{k}^{t}, \quad z_{o}^{t} \geq \sum_{k=1}^{K} \lambda_{2 k}^{t} z_{k}^{t}, \quad L_{o}^{t} \geq \sum_{k=1}^{K} \lambda_{2 k}^{t} L_{k}^{t}, \\
& \delta^{t-1} c 2_{o}^{1}+\sum_{\tau<t} \delta^{t-\tau-1} i y 2^{\tau} \geq \sum_{k=1}^{K} \lambda_{2 k}^{t} c 2_{k}^{t}, \quad \phi^{-1, t} f y_{o}^{t}+i y 1^{t}+i y 2^{t} \leq \sum_{k=1}^{K} \lambda_{2 k}^{t} y_{k}^{t}, \\
& \lambda_{1 k}^{t} \geq 0, \quad \lambda_{2 k}^{t} \geq 0, \quad k=1, \ldots, K, t=2, \ldots, T-1,
\end{aligned}
$$

and in $T$

$$
\begin{aligned}
& A_{o}^{T} \geq \sum_{k=1}^{K} \lambda_{1 k} A_{k}^{T}, \quad \gamma^{T-1} c 1_{o}^{1}+\sum_{\tau<T} \gamma^{T-\tau-1} i y 1^{\tau} \geq \sum_{k=1}^{K} \lambda_{1 k}^{T} c 1_{k}^{T}, \quad z_{o}^{T-1} \geq \sum_{k=1}^{K} \lambda_{1 k}^{T} z_{k}^{T-1}, \\
& \tilde{z}_{o}^{T-1} \geq \sum_{k=1}^{K} \lambda_{1 k}^{T} \tilde{z}_{k}^{T-1}, \quad z_{o}^{T} \leq \sum_{k=1}^{K} \lambda_{1 k}^{T} z_{k}^{T}, \quad z_{o}^{T} \geq \sum_{k=1}^{K} \lambda_{2 k}^{T} z_{k}^{T}, \quad L_{o}^{T} \geq \sum_{k=1}^{K} \lambda_{2 k}^{T} L_{k}^{T},
\end{aligned}
$$




$$
\begin{aligned}
& \delta^{T-1} c 2_{o}^{1}+\sum_{\tau<T} \gamma^{T-\tau-1} i y 2^{\tau} \geq \sum_{k=1}^{K} \lambda_{2 k}^{T} c 2_{k}^{T}, \quad \phi^{-1, T} f y_{o}^{T}+i y 1_{o}^{T}+i y 2_{o}^{T} \leq \sum_{k=1}^{K} \lambda_{2 k} y_{k}^{T}, \\
& \lambda_{1 k}^{T} \geq 0, \quad \lambda_{2 k}^{T} \geq 0, \quad k=1, \ldots, K .
\end{aligned}
$$

The choice variables for the dynamic optimization problem are the expansion factors, $\phi^{-1, t}, t=$ $1, \ldots, T$, the intensity variables for the two stages of production, $\lambda_{1 k}^{t}$ and $\lambda_{2 k}^{t}, k=1, \ldots, K$ and $t=$ $1, \ldots, T$, and the investments in research capital and physical capital, $i y 1^{t}$ and $i y 2^{t}, t=1, \ldots, T-1$.

New knowledge incorporated into publications is an intermediate product. Publications are produced in stage 1 and then used in stage 2 where they are combined with labor and physical capital to produce real GDP. Real GDP equals the sum of final consumption, investment in physical capital, and investment in R\&D capital. The goal is to maximize the sum of the expansion factors to final consumption. Investment in physical capital and investment in R\&D capital are also intermediate products; they are produced in stage 2 in $t$ and then used in $t+1$. Physical capital investment in $t$ adds to the depreciated stock of physical capital available to stage 2 in $t+1$. Investments in $\mathrm{R} \& \mathrm{D}$ add to the depreciated R\&D capital stock of stage 1 in $t+1$. Therefore, it can be possible that increasing one or both types of investment in an early period can lead to expansions in subsequent periods' final consumption that more than offsets the decline from the earlier period. It can also be possible that R\&D investment has a higher marginal contribution to final consumption than does physical capital investment. Or vice versa. The goal of our model is to find out and see if it coincides with Romer's theory.

\section{Data and model estimates}

To estimate the dynamic network model, we use pooled aggregate data on 53 countries for the years 1996-2012. The process of creating new knowledge generally occurs over more than one year as ideas are first discussed and refined, then experiments are performed and analyzed, with results presented at conferences, and finally, formalized as publications. We follow Weber and Xia (2011) and Fukuyama et al. (2016) and take a three-year moving average of authors, publications, and citations. The three-year averages along with lagged investments in physical capital and knowledge capital allow the model to be estimated for 1999-2012. Most of the input and intermediate product data for the first stage come from Bostian et al. (2018) and include counts of authors, publications, and highly cited publications for each of 18 STEM disciplines aggregated to the country level for the years 1996-2012. ${ }^{2}$ The knowledge spillover received by country $j$ equals the sum of publications across all countries minus country $j$ 's publications.

Research capital is derived from the World Bank, which reports the percentage of real GDP allocated to R\&D. We multiply this percentage by real GDP at purchasing power parity in constant (2015) dollars. Since research capital investments are not reported for some countries in some years, we interpolate missing values. Then, we take the three-year moving average of R\&D expenditures as the measure of research capital.

\footnotetext{
${ }^{2}$ The STEM disciplines from the Scopus ASJC main discipline codes are AGRI, BIOC, CENG, CHEM, COMP, DECI,
} EART, ECON, ENER, ENGI, ENVI, IMMU, MATE, MATH, MEDI, NEUR, PHAR, PHYS. 


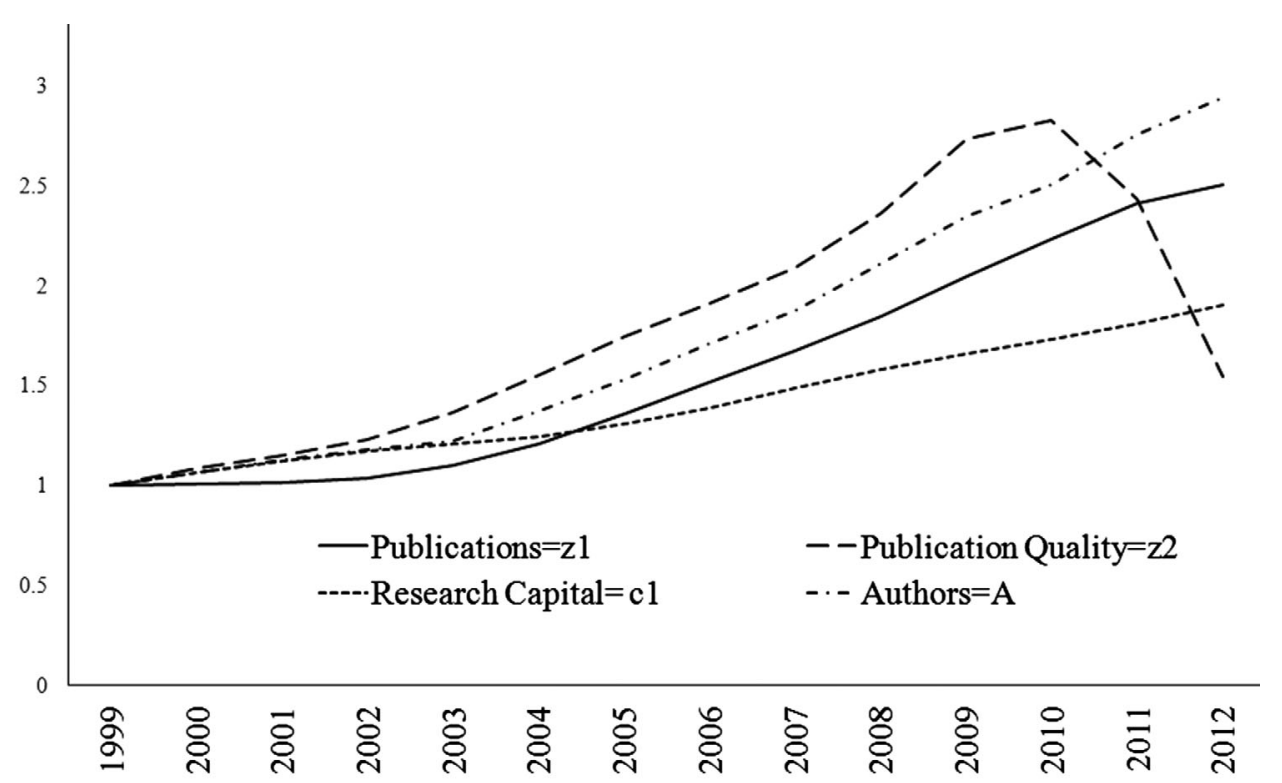

Fig. 3. Trend in knowledge inputs and outputs in 18 STEM disciplines.

The intermediate products from stage 1 (publications $-z_{1}$ and citations $-z_{2}$ ) enter stage 2 technology as inputs that are combined with labor and real physical capital to produce real GDP. These stage 2 inputs and outputs come from the Penn World Tables (see Feenstra et al., 2015). New publications from $t$ spill over to other countries in $t+1$. Our one-period lag on spillover publications is consistent with Luintal and Khan's (2017) review that international knowledge spillovers occur quickly.

Table 2 reports descriptive statistics for the pooled data and for the beginning and ending sample years, 1999 and 2012. The USA has the maximum real GDP and China the maximum employment. Average real physical capital $(c 2)$ exceeds the three-year average of R\&D expenditures $(c 1)$ by a factor of 42 . The average percentage of real GDP allocated to R\&D expenditures was $1.32 \%$. On average, authors exceed the number of publications. We measure publication quality by the number of citations in the four years after the publications occur. ${ }^{3}$ Our choice to measure citations in the four years after publication is near the midpoint of recent work by Parolo et al. (2015) who found that citations in physics, medicine, chemistry, and biology peak between two and seven years after publication. From 1999 to 2012, average real physical capital doubles and knowledge capital increases by $90 \%$. Average employment increases $15 \%$ and real final consumption increases $68 \%$.

Figure 3 graphs the trend in average publications, authors, and citations. The variables are normalized to 1 in 1999. From 1999 to 2012 average R\&D expenditures increase by a factor of 1.9 , authors increase by a factor of 2.9 , and publications increase by a factor of 2.5 . However, citations increased only 1.5 times and peaked in 2010 and then declined in 2011 and 2012. This decline in citations is due to an incomplete updating and assessment of citations, that is, citations to

\footnotetext{
${ }^{3}$ For every additional period used to measure citations, like five years instead of four, the available sample years to run the model is reduced by 1 .
} 
Table 2

Descriptive statistics, pooled data, 742 observations

\begin{tabular}{|c|c|c|c|c|c|c|}
\hline Variables & Model & Description & Mean & $\mathrm{SD}$ & Min. & Max. \\
\hline \multicolumn{7}{|c|}{ Pooled data, 742 observations $=53$ countries $\times 14$ years } \\
\hline$y$ & $\mathrm{~S}, \mathrm{D}$ & Real GDP & $1,218,000$ & $2,395,000$ & 40,000 & $15,900,000$ \\
\hline$L$ & $\mathrm{~S}, \mathrm{D}$ & Employment & 40 & 120 & 1 & 790 \\
\hline$c 2$ & S,D & Real physical capital & $3,844,000$ & $7,550,000$ & 66,000 & $54,610,000$ \\
\hline$c 1$ & S,D & Knowledge capital & 61,000 & 168,000 & 400 & $1,280,000$ \\
\hline$z_{1}$ & S,D & Publications & 42,700 & 89,100 & 860 & 707,000 \\
\hline$z_{2}$ & S,D & Citations & 275,000 & 675,000 & 2100 & $6,300,000$ \\
\hline$\tilde{z}^{t-1}$ & S,D & Spillover publications & $1,918,000$ & 651,000 & 537,000 & $3,280,000$ \\
\hline$z_{1}^{t-1}$ & S,D & Past own publications & 40,000 & 84,000 & 770 & 701,000 \\
\hline$A$ & S,D & Authors & 88,000 & 190,000 & 1600 & $1,530,000$ \\
\hline$f y=y-i y 1-i y 2$ & $\mathrm{D}$ & Real final consumption & 880,000 & $1,660,000$ & 27,000 & $12,160,000$ \\
\hline$i y 1$ & $\mathrm{D}$ & $\mathrm{R} \& \mathrm{D}$ investment & 22,000 & 58,100 & 200 & 400,000 \\
\hline$i y 2$ & $\mathrm{D}$ & Physical capital investment & 320,000 & 730,000 & 5000 & $6,940,000$ \\
\hline \multicolumn{7}{|l|}{1999} \\
\hline$y$ & S,D & Real GDP & 90,9000 & $1,890,000$ & 40,000 & $12,510,000$ \\
\hline$L$ & S,D & Employment & 40 & 110 & 1 & 700 \\
\hline$c 2$ & S,D & Real physical capital & $2,600,000$ & $5,140,000$ & 66,000 & $34,400,000$ \\
\hline$c 1$ & S,D & Knowlecdge capital & 44,000 & 132,000 & 400 & 899,000 \\
\hline$z_{1}$ & S,D & Publications & 27,000 & 61,000 & 860 & 413,000 \\
\hline$z_{2}$ & S,D & Citations & 154,000 & 430,000 & 2100 & $3,000,000$ \\
\hline$\tilde{z}^{t-1}$ & S,D & Spillover publications & 930,000 & 63,000 & 537,000 & 960,000 \\
\hline$z_{1}^{t-1}$ & S,D & Past own publications & 27,000 & 63,000 & 770 & 424,000 \\
\hline$A$ & S,D & Authors & 50,000 & 110,000 & 1600 & 720,000 \\
\hline$f y=y-i y 1-i y 2$ & $\mathrm{D}$ & Real final consumption & 675,000 & $1,350,000$ & 27,000 & $8,910,000$ \\
\hline$i y 1$ & $\mathrm{D}$ & $\mathrm{R} \& \mathrm{D}$ investment & 15,000 & 47,000 & 200 & 318,000 \\
\hline$i y 2$ & $\mathrm{D}$ & Physical capital investment & 219,000 & 496,000 & 5000 & $3,290,000$ \\
\hline \multicolumn{7}{|l|}{2012} \\
\hline$y$ & S,D & Real GDP & $1,590,000$ & $3,019,442$ & 54,200 & $15,900,000$ \\
\hline$L$ & S,D & Employment & 44 & 126 & 1 & 790 \\
\hline$c 2$ & S,D & Real physical capital & $5,650,000$ & $10,360,000$ & 297,000 & $54,610,000$ \\
\hline$c 1$ & S,D & Knowledge capital & 83,000 & 207,000 & 1900 & $1,280,000$ \\
\hline$z_{1}$ & S,D & Publications & 68,000 & 128,000 & 5000 & 707,000 \\
\hline$z_{2}$ & S,D & Citations & 238,000 & 484,000 & 8800 & $3,200,000$ \\
\hline$\tilde{z}^{t-1}$ & S,D & Spillover publications & $3,220,000$ & 120,000 & $2,580,000$ & $3,280,000$ \\
\hline$z_{1}^{t-1}$ & S,D & Past own publications & 66,000 & 125,000 & 4670 & 701,000 \\
\hline$A$ & S,D & Authors & 150,000 & 290,000 & 8000 & $1,530,000$ \\
\hline$f y=y-i y 1-i y 2$ & $\mathrm{D}$ & Real final consumption & $1,130,000$ & $2,020,000$ & 39,800 & $12,160,000$ \\
\hline$i y 1$ & $\mathrm{D}$ & $\mathrm{R} \& \mathrm{D}$ investment & 29,000 & 712,000 & 666 & 400,000 \\
\hline$i y 2$ & $\mathrm{D}$ & Physical capital investment & 434,000 & $1,050,000$ & 13,000 & $6,950,000$ \\
\hline
\end{tabular}

Real GDP means real physical capital and knowledge capital are millions of constant 2015 dollars. Employment is millions of workers.

$\mathrm{S}$, D means variable is in static and dynamic model; D means variable is in dynamic model. 
Table 3

Static estimates of stage 1 and network efficiency

\begin{tabular}{llll}
\hline & With citations & & Without citations \\
\cline { 2 - 3 } Year & Stage 1 & Stage 1 & Network \\
\hline 1999 & 0.975 & 0.974 & 0.823 \\
2000 & 0.982 & 0.979 & 0.800 \\
2001 & 0.974 & 0.967 & 0.794 \\
2002 & 0.979 & 0.971 & 0.783 \\
2003 & 0.975 & 0.972 & 0.769 \\
2004 & 0.973 & 0.971 & 0.766 \\
2005 & 0.969 & 0.967 & 0.750 \\
2006 & 0.972 & 0.970 & 0.727 \\
2007 & 0.971 & 0.967 & 0.739 \\
2008 & 0.973 & 0.969 & 0.682 \\
2009 & 0.965 & 0.961 & 0.753 \\
2010 & 0.968 & 0.963 & 0.732 \\
2011 & 0.961 & 0.958 & 0.694 \\
2012 & 0.964 & 0.958 & 0.695 \\
\hline
\end{tabular}

publications that occurred in 2011 and 2012 were not updated in the last years of our sample, 2015 and 2016.

We estimate static efficiency by country and year for stage 1 two ways: with two intermediate products of publications and citations and with a single intermediate product of publications. The efficiency estimates are in Table 3. By construction, average efficiency is always greater when controlling for citations than when citations are not included. Nonetheless, output technical efficiency ranges between 0.96 and 0.98 and the estimates with and without citations are close in value. In 2001, the two efficiency estimates have a Spearman rank correlation coefficient of 0.85 . In the other years, the Spearman rank correlation coefficients are greater than 0.93 . Furthermore, the citations to published work from 2011 and 2012 were not completely updated and assessed in 2015 and 2016. Therefore, given the potential for bias in citations, and the significantly high correlation between the two models, we opt for a more parsimonious model and do not include citations as a quality control in the dynamic model estimates presented below.

Average static network efficiency is 0.82 in 1999, but then trends down to 0.68 in 2008. Average efficiency rebounds to 0.75 in 2009, but declines to 0.69 in 2011 and 2012.

We estimate the dynamic model for a three-year horizon assuming equal weights for each period: $\Psi^{t}=1 .^{4}$ We experimented with several rates of depreciation for knowledge capital and physical capital with qualitatively similar results. We settled on a depreciation rate for knowledge capital of $1-\gamma=0.33$ and a depreciation rate for physical capital of $1-\delta=0.10$. Dynamic efficiency, $E F F$, equals the average sum of the reciprocals of the expansion factors, that is, $E F F=\frac{1}{3}\left(\frac{1}{\phi^{t}}+\frac{1}{\phi^{t+1}}+\right.$ $\left.\frac{1}{\phi^{t+2}}\right)$. The dynamic estimates are presented in Table 4 .

Table 4 compares the dynamic capital (DC) estimates from (13), (14), and (15) with the static network estimates presented in Table 3 . Since the status quo amounts of research capital to stage 1

\footnotetext{
${ }^{4}$ We also estimated the model using discount rates of $r=0.05$ and $r=0.10$ and obtained similar estimates. 
Table 4

Efficiency estimates

\begin{tabular}{llll}
\hline Years & Dynamic capital (DC) & Dynamic investment (DI) & Capital preservation (CP) \\
\hline $1999-2001$ & 0.673 & 0.687 & 0.702 \\
$2000-2002$ & 0.670 & 0.666 & 0.718 \\
$2001-2003$ & 0.687 & 0.633 & 0.739 \\
$2002-2004$ & 0.692 & 0.622 & 0.776 \\
$2003-2005$ & 0.711 & 0.633 & 0.799 \\
$2004-2006$ & 0.729 & 0.642 & 0.792 \\
$2005-2007$ & 0.721 & 0.594 & 0.777 \\
$2006-2008$ & 0.691 & 0.604 & 0.708 \\
$2007-2009$ & 0.679 & 0.645 & 0.730 \\
$2008-2010$ & 0.677 & 0.676 & 0.749 \\
$2009-2011$ & 0.708 & 0.705 & 0.769 \\
$2010-2012$ & 0.701 & 0.642 & 0.746 \\
All years & 0.695 & 0.646 & 0.751 \\
\hline
\end{tabular}

and physical capital to stage 2 are feasible, but not necessarily optimal in the dynamic model, average efficiency in the dynamic model should be no greater than the three-year average efficiency for the static model. For example, average dynamic efficiency is 0.673 during 1999-2001, while average static efficiency for those same three years is $(0.823+0.800+0.794) / 3=0.806$. Thus, an optimal reallocation of research capital and physical capital across three years expands the technology set allowing greater potential output. Average efficiency for the DC model ranges from 0.67 during 2000-2002 to 0.729 during 2004-2006.

In a precursor to this paper, two alternative specifications of research capital and physical capital were considered. The "dynamic investment" (DI) model follows Färe et al. (2018). In this specification, we drop the constraints for the stocks of research capital and physical capital and replace them with their respective flows of research investments and physical capital investments. Our "capital preservation" (CP) model follows Nemoto and Goto (2003), Emrouznejad and Thanassoulis (2005), and Ouellette and Yan (2008). In this specification, we take the stocks of research capital and physical capital as values to be preserved for future use. ${ }^{5}$ Dynamic efficiencies for these two alternative specifications are reported in Table 4. Efficiency averages 0.751 for the CP model, versus 0.695 for the DC model and 0.646 for the DI model. The CP model has the highest average efficiency in every three-year period. In contrast, the DI model estimates the lowest average efficiency in every threeyear period except 1999-2001. The DC and CP models show greater average efficiency in 2010-2012 than in 1999-2001. In contrast, the DI model shows a downward trend in average efficiency. The efficiency estimates for the three models exhibit positive significant correlation coefficients between the three models in every year: between 0.78 and 0.91 for the DC and CP models; between 0.55 and 0.77 for the DC and DI models; and between 0.70 and 0.87 for the DI and CP models.

We are further interested in examining Romer's theory that there will be underinvestment in R\&D capital relative to physical capital because of the public good characteristics of knowledge. By construction, the CP model ensures that the optimal investments in physical capital and research capital are great enough to preserve the two capital stocks to be at least as great as their actual levels

${ }^{5}$ Details of the DI model and the CP model are found in Bostian et al. (2018). 
Table 5

Terminal values of actual and optimal research capital and physical capital

\begin{tabular}{|c|c|c|c|c|c|c|}
\hline \multirow[b]{2}{*}{ Years } & \multicolumn{2}{|l|}{ Actual } & \multicolumn{2}{|c|}{ Optimal } & \multirow[b]{2}{*}{$\frac{c 1^{T}}{c 2^{T}}$} & \multirow[b]{2}{*}{$\frac{c 1^{T *}}{c 2^{T *}}$} \\
\hline & $c 1^{T}$ & $c 2^{T}$ & $c 1^{T *}$ & $c 2^{T *}$ & & \\
\hline 1999-2001 & 49,100 & $2,740,000$ & 39,700 & $1,240,000$ & 0.012 & 0.020 \\
\hline 2000-2002 & 51,200 & $2,790,000$ & 40,600 & $1,200,000$ & 0.013 & 0.020 \\
\hline 2001-2003 & 52,800 & $2,930,000$ & 43,900 & $1,240,000$ & 0.013 & 0.021 \\
\hline 2002-2004 & 54400 & $3,180,000$ & 43,200 & $1,360,000$ & 0.012 & 0.020 \\
\hline 2003-2005 & 57,300 & $3,500,000$ & 44,400 & $1,490,000$ & 0.012 & 0.018 \\
\hline 2004-2006 & 60,700 & $3,900,000$ & 47,100 & $1,650,000$ & 0.011 & 0.018 \\
\hline 2005-2007 & 65,000 & $4,250,000$ & 49,700 & $1,820,000$ & 0.011 & 0.016 \\
\hline 2006-2008 & 69,200 & $4,540,000$ & 52,200 & $2,120,000$ & 0.011 & 0.017 \\
\hline 2007-2009 & 72,600 & $4,730,000$ & 55,400 & $2,400,000$ & 0.011 & 0.017 \\
\hline 2008-2010 & 75,600 & $4,980,000$ & 58,000 & $2,460,000$ & 0.011 & 0.018 \\
\hline 2009-2011 & 79000 & $5,350,000$ & 60,300 & $1,970,000$ & 0.011 & 0.020 \\
\hline 2010-2012 & 83,100 & $5,650,000$ & 62,400 & $2,100,000$ & 0.011 & 0.019 \\
\hline All years & 64,200 & $4,040,000$ & 49,000 & $1,750,000$ & 0.012 & 0.018 \\
\hline
\end{tabular}

in the terminal period, so this model does not shed any light on Romer's theory. In turn, the two stocks of capital are omitted from the DI model, as this model includes only the flows of investment in R\&D and physical capital. Given the high correlations between these models, we focus on the DC model for the rest of this paper.

The optimal amounts of research capital and physical capital in $T=3$ (the terminal period) are calculated as

$$
\begin{aligned}
c 1_{k}^{3 *} & =\gamma^{2} c 1_{k}^{1}+\gamma i y 1^{1 *}+i y 1^{2 *} \\
\text { and } c 2_{k}^{* 3} & =\delta^{2} c 2^{1}+\delta i y 2^{1 *}+i y 2^{2 *}
\end{aligned}
$$

Table 5 shows that on average, both types of capital would shrink relative to their actual values as more resources are pushed into producing final consumption. However, their relative shares would also change as shown in the last two columns. The optimal ratio of research to physical capital is greater than the actual ratio of research to physical capital in every year. The results are even more pronounced in some countries such as the United States where optimal research capital investments are greater than actual research capital investments in every year. In addition, the optimal physical capital stock in the United States would shrink relative to its actual level. In the United States, the increase in research capital and decrease in physical capital relative to actual levels would result in an optimal research to physical capital ratio almost twice as great as the actual ratio. For instance, during 1999-2001, the terminal period ratio of actual knowledge capital to actual physical capital is 0.027 but the ratio of optimal knowledge capital to optimal physical capital is 0.042 . In our last three-year period, 2010-2012, the actual ratio is 0.026 , but the optimal ratio is 0.053 . In relative terms then, our empirical results are consistent with Romer's (1990) theory that predicts underinvestment in research capital because of its spillover effects and because prices in stage 2 are greater than the competitive level. 
Table 6

Actual and optimal ratio of research capital $(c 1)$ to physical capital $(c 2)$ for six countries with optimal investment in research capital

\begin{tabular}{lll}
\hline Country & $\begin{array}{l}\text { Actual ratio } \\
c 1^{T} / c 2^{T}\end{array}$ & $\begin{array}{l}\text { Optimal ratio } \\
c 1^{* T} / c 2^{* T}\end{array}$ \\
\hline China & 0.013 & 0.039 \\
Iran & 0.005 & 0.010 \\
New Zealand & 0.012 & 0.024 \\
Saudi Arabia & 0.002 & 0.003 \\
United Kingdom & 0.015 & 0.030 \\
United States & 0.025 & 0.048 \\
Six country mean & 0.012 & 0.026 \\
Mean for other 47 countries & 0.012 & 0.017 \\
\hline
\end{tabular}

Six countries (China, Iran, New Zealand, Saudi Arabia, United Kingdom, and United States) have optimal R\&D investments that are equal to actual R\&D investments in every three-year period 1999-2001 and 2010-2012, but these same countries overinvested in physical capital relative to knowledge capital. Table 6 reports means of the actual and optimal ratios of R\&D capital $\left(c_{1}\right)$ to physical capital $\left(c_{2}\right)$ in the terminal period $(T=3)$ and compares them to the mean ratios for the other 47 countries in the sample. The optimal amount of physical capital in the terminal period is smaller than the actual quantity for the six countries. Thus, the final outputs could be produced using the same amount of R\&D capital and labor, but less physical capital. Therefore, the excess physical capital gets pushed into the final output via the expansion factors $\lambda^{t}$. In addition, the six countries account for $48-50 \%$ of actual cumulative R\&D spending among all 53 countries, and the two biggest economies, United States and China, account for $44-46 \%$ of all R\&D spending. These results point to an overallocation of resources to physical capital. In addition, the work by Peri et al. (2015) found that $30-50 \%$ of productivity growth in U.S. cities was due to the growth of foreign STEM researchers. Our model uses the number of authors in a country as a fixed input in the research sector, but does not consider reallocations of STEM researchers across countries. Allowing reallocation of researchers between countries might be another way of increasing final output, but this reallocation is not part of our model and in practice is restricted by governments' immigration policies.

Table 7 reports the ratios by year for the six countries reported earlier and for the other 47 countries. For the six research-efficient countries the actual ratios of R\&D to physical capital, average $1.2 \%$, but with optimal ratios that range from $1.9 \%$ in $2007-2009$ to $3.2 \%$ in $2010-2012$. The other 47 countries have similar actual ratios of R\&D to physical capital, about $1.2 \%$, but the optimal terminal period ratios of R\&D to physical capital range only from about $1.5 \%$ to almost $2 \%$. Thus, it appears that the six research-efficient countries, especially China and the United States should allocate more to $R \& D$ capital relative to physical capital.

\section{Conclusions}

The transmission of existing knowledge and the production of new knowledge are important drivers of productivity growth. We construct a dynamic network technology where knowledge is an 
Table 7

Ratios of research capital to knowledge capital by year

\begin{tabular}{|c|c|c|c|c|}
\hline \multirow[b]{2}{*}{ Period } & \multicolumn{2}{|l|}{6 Countries } & \multicolumn{2}{|l|}{47 Countries } \\
\hline & $\begin{array}{l}\text { Actual ratio } \\
c 1^{T} / c 2^{T}\end{array}$ & $\begin{array}{l}\text { Optimal ratio } \\
c 1^{* T} / c 2^{* T}\end{array}$ & $\begin{array}{l}\text { Actual ratio } \\
c 1^{T} / c 2^{T}\end{array}$ & $\begin{array}{l}\text { Optimal ratio } \\
c 1^{* T} / c 2^{* T}\end{array}$ \\
\hline 1999-2001 & 0.012 & 0.025 & 0.012 & 0.019 \\
\hline 2000-2002 & 0.013 & 0.027 & 0.013 & 0.019 \\
\hline 2001-2003 & 0.013 & 0.027 & 0.013 & 0.020 \\
\hline 2002-2004 & 0.012 & 0.027 & 0.012 & 0.019 \\
\hline 2003-2005 & 0.012 & 0.026 & 0.012 & 0.017 \\
\hline 2004-2006 & 0.012 & 0.025 & 0.011 & 0.017 \\
\hline 2005-2007 & 0.012 & 0.025 & 0.011 & 0.015 \\
\hline 2006-2008 & 0.012 & 0.023 & 0.011 & 0.017 \\
\hline 2007-2009 & 0.012 & 0.019 & 0.011 & 0.016 \\
\hline 2008-2010 & 0.012 & 0.021 & 0.011 & 0.017 \\
\hline 2009-2011 & 0.012 & 0.032 & 0.011 & 0.018 \\
\hline 2010-2012 & 0.012 & 0.032 & 0.011 & 0.017 \\
\hline
\end{tabular}

intermediate product. The network model consists of two stages where knowledge, measured as the number of scientific publications in STEM fields, is produced in stage 1 and then used as an input in stage 2 where it is combined with labor and physical capital to produce final consumption and two types of investment spending: investment in new research capital and investment in new physical capital. A country experiences dynamic effects in several ways. First, the two types of investment spending that occur in period $t$ augment the country's production possibilities in $t+1$. Second, new knowledge (publications) produced by a country in $t$ spills over and augments the country's production in period $t+1$. Third, although new knowledge produced by a country in $t$ can only be used by the same country in $t$, by period $t+1$ that same knowledge spills over to other countries as it becomes more widely disseminated.

We use panel data on 53 countries during 1999-2012 to estimate the model using DEA. Dynamic efficiency averages about $70 \%$ compared with the average static efficiency of about $75 \%$. Thus, outputs could be increased the most by countries realizing greater technical efficiency in converting publications and other inputs into real GDP. But there are still some gains that could be realized by an intertemporal reallocation of the investments in research capital and physical capital. For the 53 countries, the average ratio of research capital to physical capital ranges is about 0.012 and the optimal ratio of research capital to physical capital is 0.019 . This result is consistent with Romer's (1990) theory of endogenous technical change, which showed that private firms will tend to underallocate resources to research because of the public good properties of knowledge.

Our dynamic optimization problem takes a country's research capital as given in the initial period and that capital depreciates over time. Each subsequent period's capital equals depreciated capital plus new research investment. A country is research efficient when the optimal amount of research capital (depreciated capital plus new investment) equals the actual amount of research capital and the country produces on the frontier of stage 1 technology. Six countries - China, United States, United Kingdom, Iran, Saudia Arabia, and New Zealand - produced on the research frontier every 
year. For the six research-efficient countries, the ratio of optimal R\&D capital to optimal physical capital increases from around 0.025 in $1999-2001$ to 0.032 in 2010-2012. The same ratio trends downward for the other 47 countries, from 0.019 to 0.0165 . China and the United States accounted for $48-50 \%$ of cumulative R\&D spending among the 53 countries and these two countries have the highest average ratio of optimal R\&D to optimal physical capital, $3.9 \%$ and $4.8 \%$, respectively.

In 2000, European countries set an ambitious goal of allocating 3\% of GDP to R\&D by 2010 in what is known as the "Lisbon strategy" (Bongardt and Torres, 2013). Only a few countries in our sample met this goal by 2010: Denmark, Finland, Sweden, and Switzerland in Europe, along with Korea, Japan, and Israel. Our results indicate that increasing R\&D investments relative to capital investments can increase potential outputs. But we caution that those resources would have to be used efficiently to reach potential. Since our model estimates that countries are on average only $70 \%$ efficient, some of that potential output will likely disappear as various inefficiencies arise. Nonetheless, countries such as China, Korea, and Iran have increasingly allocated resources to R\&D and have also realized relatively strong economic growth (Zhou and Leydesdorf, 2006; Moed and Galevi, 2014; Moed, 2016).

We offer several caveats of our study. First, the data are highly aggregated, which masks most of the interactions between the actual researchers within and across countries and disciplines. Second, our model might suffer from a "curse of dimensionality" as the relatively small number of countries, and a large number of outputs and inputs probably puts an upward bias to the efficiency estimates. Daraio and Simar (2007) propose a factorial analysis to reduce this curse, and future research might usefully incorporate factor analysis into the dynamic network model. Third, our model has used only publications as the knowledge output. Private R\&D divisions of businesses and increasingly, universities, also produce patents, which is another knowledge output. Future research might usefully account for these patents in a dynamic network model.

\section{Acknowledgments}

We thank participants at the 6th International Workshop on "Efficiency in Education, Health and other Public Services" for discussion on an earlier draft of this paper. Data were provided by Elsevier within the EBRP project with financial support from the Italian Ministry of Education and Research (through the PRIN project no. 2015RJARX7) of Sapienza University of Rome (through the Sapienza awards no. 6H15XNFS).

\section{References}

Adams, J.D., 1990. Fundamental stocks of knowledge and productivity growth. Journal of Political Economy 98, 4, 673-702.

Agasisti, T., Haelermans, C., 2016. Comparing efficiency of public universities among European countries: different incentives lead to different performances. Higher Education Quarterly 70, 1, 81-104.

Aksnes, D.W., Sivertsen, G., van Leeuwen, T.N., Wendt, K.K., 2017. Measuring the productivity of national R\&D systems: challenges in cross-national comparisons of R\&D input and publication output indicators. Science and Public Policy 44, 2, 246-258.

Azoulay, P., Ding, W., Stuart, T., 2009. The impact of academic patenting on the rate, quality and direction of (public) research. Journal of Industrial Economics 57, 4, 637-676. 
Bogetoft, P., Färe, R., Grosskopf, S., Hayes, K., Taylor, L., 2009. Dynamic network DEA: an illustration. Journal of the Operations Research Society of Japan 52, 2, 147-162.

Boldrin, M., Levine, D.K., 2009. A model of discovery. American Economic Review: Papers and Proceedings 99, 2, $337-342$.

Bongardt, A., Torres, F., 2013. Lisbon strategy. In Jones, E., Menon, A., Weatherill, S. (eds) The Oxford Handbook of the European Union. Oxford University Press, Oxford, pp. 469-483.

Bostian, M.B., Daraio, C., Färe, R., Grosskopf, S., Grazia Izzo, M., Leuzzi, L., Ruocco, G., Weber, W.L., 2018. Inference for nonparametric productivity networks: a pseudo-likelihood approach. Presented at APPC Seoul, Korea, July 2018.

Bostian, M.B., Daraio, C., Grosskopf, S., Weber, W.L., 2018. Knowledge production technologies. Mimeo.

Catalano, G., Daraio, C., Diana, M., Gregori, M., Matteucci, G., 2019. Efficiency, effectiveness and impacts assessment in the rail transport sector: a state-of-the-art critical analysis of current research. International Transactions in Operational Research 26, 1, 5-40.

Chen, Y.C., Chiu, Y.H., Chiu, C.J., 2020. The performance evaluation of banks considering risk: an application of undesirable relation network DEA. International Transactions in Operational Research 27, 2, 1101-1120.

Comanor, W.S., Scherer, F.M., 1969. Patent statistics as a measure of technical change. Journal of Political Economy 77 , 3, 392-398.

Daraio, C., Fabbri, F., Gavazzi, G., Izzo, M.G., Leuzzi, L., Quaglia, G., Ruocco, G., 2018. Assessing the interdependencies between scientific disciplinary profiles. Scientometrics 116, 3, 1785-1803.

Daraio, C., Kerstens, K., Nepomuceno, T., Sickles, R.C., 2020. Empirical surveys of frontier applications: a meta-review. International Transactions in Operational Research 27, 2, 709-738.

Daraio, C., Simar, L., 2007. Advanced Robust and Nonparametric Methods in Efficiency Analysis: Methodology and Applications. Springer, New York.

Emrouznejad, A., Thanassoulis, E., 2005. A mathematical model for dynamic efficiency using data envelopment analysis. Applied Mathematics and Computation 160, 2, 363-378.

Fabrizio, K.R., DiMinin, A., 2008. Commercializing the laboratory: faculty patenting and the open science environment. Research Policy 37, 914-931.

Fallah-Fini, S., Triantis, K., Johnson, A.L., 2014. Reviewing the literature on non-parametric dynamic efficiency measurement: state of the art. Journal of Productivity Analysis 41, 51-67.

Färe, R., Grosskopf, S., 1996a. Intertemporal Production Frontiers: With Dynamic DEA. Kluwer, Boston, MA.

Färe, R., Grosskopf, S., 1996b. Productivity and intermediate products: a frontier approach. Economics Letters 50, 65-70.

Färe, R., Grosskopf, S., 1998. Efficiency and productivity in rich and poor countries. In Jensen, B.S., Wong, K. (eds) Dynamics, Economic Growth and International Trade. University of Michigan Press, Ann Arbor, MI.

Färe, R., Grosskopf, S., 2000. Network DEA. Socioeconomic Planning Sciences 34, 35-49.

Färe, R., Grosskopf, S., Margaritis, D., Weber, W., 2012. Technological change and timing reductions in greenhouse gas emissions. Journal of Productivity Analysis 37, 3, 205-216.

Färe, R., Grosskopf, S., Margaritis, D., Weber, W.L., 2018. Dynamic efficiency and productivity: modeling and an illustration. In Grifell-Tatjé, E., Lovell, C.A.K., Sickles, R. (eds) The Oxford Handbook of Productivity Analysis. Oxford University Press, Oxford.

Feenstra, R., Inklaar, R., Timmer, M.P., 2015. The next generation of the Penn World Table. American Economic Review $105,10,3150-3182$.

Foray, D., 2004. Economics of Knowledge. MIT Press, Cambridge, MA.

Fukuyama, H., Weber, W.L., 2015. Measuring Japanese bank performance: a dynamic network DEA approach. Journal of Productivity Analysis 44, 3, 249-264.

Fukuyama, H., Weber, W.L., Xia, Y., 2016. Time substitution and network effects with an application to nanobiotechnology policy for US universities. Omega: The International Journal of Management Science 60, 34-44.

Gralka, S., Wohlrabe, K., Bornmann, L., 2018. How to measure research efficiency in higher education? Research grants vs. publication output. CESifo Working Paper No. 7055, Category 5: Economics of Education. Available at https://ssrn.com/abstract $=3210550$.

Grosskopf, S., Hayes, K., Taylor, L.L., Weber, W.L., 2017. Would weighted-student funding enhance intra-district equity in Texas? A simulation using DEA. Journal of the Operational Research Society 68, 4, 377-389. 
Hsiao, B., Shu, L., Chou, F.Y., 2019. Assessing the efficiency of the accounting industry using multiactivity network DEA: evidence from Taiwan. International Transactions in Operational Research 26, 6, 2362-2386.

Hvide, H.K., Jones, B.F., 2018. University innovation and the professor's privilege. American Economic Review 108, 7 , 1860-1898.

Ioannidis, J.P.A., 2005. Why most published research findings are false. PLoS Medicine 2, 8, 696-701.

Ioannidis, J.P.A., Stanley, T.D., Doucouliagos, H., 2017. The power of bias in economics research. The Economic Journal 127, F236-F265.

Jaffe, A.B., 1989. Real effects of academic research. American Economic Review 79, 5, 957-970.

Johnes, G., Johnes, J., 1993. Measuring the research performance of UK economics departments: an application of data envelopment analysis. Oxford Economic Papers 45, 2, 332-347.

Jones, C.I., 2002. Sources of U.S. economic growth in a world of ideas. American Economic Review 92, 1, $220-239$.

Just, R.E., Huffman, W.E., 2009. The economics of universities in a new age of funding options. Research Policy 38, 1102-1116.

Kao, C., 2014. Network data envelopment analysis: a review. European Journal of Operational Research 239, 1, 1-16.

Kao, C., 2017. Network Data Envelopment Analysis. Springer, Berlin.

Kealey, T., 1996. The Economic Laws of Scientific Research. Palgrave Macmillan, London.

King, D.A., 2004. The scientific impact of nations. Nature 430, 311-316.

Lansink, A.O., Stefanou, S., Serra, T., 2015. Primal and dual dynamic Luenberger productivity indicators. European Journal of Operational Research 241, 1, 555-563.

Mariz, F.B.A.R., Almeida, M.R., Aloise, D., 2018. A review of dynamic data envelopment analysis: state of the art and applications. International Transactions in Operational Research 25, 2, 469-505.

Moed, H.F., 2016. Iran's scientific dominance and the emergence of South-East Asian countries as scientific collaborators in the Persian Gulf Region. Scientometrics 108, 305-314.

Moed, H.F., Galevi, G., 2014. Tracking scientific development and collaborations - the case of 25 Asian countries. Research Trends. Available at https://www.researchtrends.com/issue-38-september-2014/tracking-scientific-developmentand-collaborations-the-case-of-25-asian-countries/.

Moreno, P., Lozano, S., 2018. Super SBI dynamic network DEA approach to measuring efficiency in the provision of public services. International Transactions in Operational Research 25, 2, 715-735.

Mowery, D.C., Sampat, B.N., 2005. The Bayh-Dole Act of 1980 and university-industry technology transfer: a model for other OECD governments? In Link, A.N., Scherer, F.M. (eds) Essays in Honor of Edwin Mansfield: The Economics of $R \& D$, Innovation and Technological Change. Springer, Berlin.

Narbón-Perpiñá, I., De Witte, K., 2018. Local governments' efficiency: a systematic literature review-part I. International Transactions in Operational Research 25, 2, 431-468.

Nemoto, J., Goto, M., 2003. Measurement of dynamic efficiency in production: an application of data envelopment analysis to Japanese electric utilities. Journal of Productivity Analysis 19, 191-210.

Ouellette, P., Yan, L., 2008. Investment and dynamic DEA. Journal of Productivity Analysis 29, 235-247.

Parolo, P.D.B., Pan, R.K., Ghosh, R., Huberman, B.A., Kaski, K., Fortunato, S., 2015. Attention decay in science. Journal of Informetrics 9, 4, 734-745.

Peri, G., Shih, K., Sparber, C., 2015. STEM workers, H-1B visas and productivity in US cities. Journal of Labor Economics 33,3, S225-S255.

Perkmann, M., Tartari, V., McKelvey, M., Autio, E., Broström, A., D’Este, P., Fini, R., Geuna, A., Grimaldi, R., Hughes, A., Krabel, S., Kitson, M., Llerena, P., Lissoni, F., Salter, A., Sobrero, M., 2013. Academic engagement and commercialisation: a review of the literature on university-industry relations. Research Policy 42, 423-442.

Prieto, A.M., Zofío, J.L., 2007. Network DEA efficiency in input-output models: with an application to OECD countries. European Journal of Operational Research 178, 292-304.

Ramsey, F.P., 1928. A mathematical theory of saving. Economic Journal 38, 543-559.

Romer, P.M., 1990. Endogenous technological change. Journal of Political Economy 98, 5, S71-S102.

Rothwell, J., 2013. The Hidden STEM Economy. Metropolitan Policy Program, Brookings Institution, Washington, DC.

Sacoto, S.A., Cook, W.D., Delgado, H.C., Castorena, D.G., 2015. Time-staged outputs in DEA. Omega: The International Journal of Management Science 55, 1-9.

Sengupta, J.K., 1996. Dynamic aspects of data envelopment analysis. Economic Notes 25, 1, 143-164.

(C) 2019 The Authors. International Transactions in Operational Research (C) 2019 International Federation of Operational Research Societies 
Serra, T.A., Lansink, O., Stefanou, S.E., 2011. Measurement of dynamic efficiency: a directional distance function parametric approach. American Journal of Agricultural Economics 93, 3, 756-767.

Shen, Z., Yang, L., Pei, J., Li, M., Wu, C., Bao, J., Wei, T., Di, Z., Rousseau, R., Wu, J., 2016. Interrelations among scientific fields and their relative influences revealed by an input-output analysis. Journal of Informetrics 10, 82-97.

Shephard, R.W., 1970. Theory of Cost and Production Functions. Princeton University Press, Princeton, NJ.

Silva, E., Lansink, A.O., Stefanou, S.E., 2015. The adjustment-cost model of the firm: duality and productive efficiency. International Journal of Production Economics 168, 245-256.

Silva, E., Stefanou, S.E., 2003. Nonparametric dynamic production analysis and the theory of cost. Journal of Productivity Analysis 19, 1, 5-32.

Solow, R., 1956. A contribution to the theory of economic growth. Quarterly Journal of Economics 70, 1, 65-94.

Tartari, V., Perkmann, M., Salter, A., 2014. In good company: the influence of peers on industry engagement by academic scientists. Research Policy 43, 1189-1203.

Thursby, J.G., Thursby, M.C., 2002. Who is selling the ivory tower? Sources of growth in university licensing. Management Science 48, 1, 90-104.

Tran, C.D.T., Villano, R.A., 2018. Measuring efficiency of Vietnamese public colleges: an application of the DEA-based dynamic network approach. International Transactions in Operational Research 25, 2, 683-703.

Weber, W.L., 2019. Network production and shadow prices of knowledge outputs. In Färe, R., Grosskopf, S., Margaritis, D. (eds) Pricing Non-Marketed Goods Using Distance Functions, World Scientific, Singapore.

Weber, W.L., Xia, Y., 2011. The productivity of nanobiotechnology research and education in US universities. American Journal of Agricultural Economics 93, 4, 1151-1167.

Zhou, P., Leydesdorff, L., 2006. The emergence of China as a leading nation in science. Research Policy 35, 83-104. 